\title{
THE QUANTITATIVE ANALYSIS OF COPPER IN IRON BASED ALLOYS
}

\author{
G.M. WORRALL and G.D.W. SMITH
}

Department of Metallurgy and Science of Materials, University of oxford, Parks Road, GB-Oxford OXI 3PH, Great Britain

\begin{abstract}
The quantitative analysis of low copper levels in iron based alloys has been investigated using the Oxford VG FIM 100 atom probe, in particular the optimum experimental conditions necessary to give the correct stoichiometry. Variables investigated include pulse fraction, specimen temperature, crystallographic plane, the presence of image gas and the effect of laser-pulses compared to voltage pulses. Careful control of certain experimental conditions, especially temperature and pulse fraction, is necessary to give the correct copper level. These results are being applied to an investigation of the role of copper in the embrittlement of low alloy steels.
\end{abstract}

\section{1 - INTRODUCTION}

The role of copper as an embrittling element in steel is one of increasing concern, in particular the enhanced radiation induced embrittlement at around $290^{\circ} \mathrm{C}$ observed with levels as low as $0.4 \mathrm{wt} . \% \mathrm{Cu}[1]$. The hardening defects in these alloys have been studied by TEM and neutron scattering techniques $[2,3]$. Current theories suggest that these are either microvoids, formed by the irradiation process and stabilised by copper, or copper precipitates, formed at these temperatures by enhanced diffusion due to the presence of irradiation induced vacancies. Extensive atom probe analysis of unirradiated $\mathrm{Fe}-\mathrm{Cu}$ alloys was undertaken some years ago by Goodman and Brenner [4], and recently, small copper rich regions have been detected in irradiated steels by Brenner et al. [5]. However, apparently spurious atom probe detection efficiencies for copper in Cu-Ni-Fe alloys have been reported [6], and it has become clear that care must be taken in order to obtain quantitative atom probe analyses from a wide range of materials $[7,8]$. We have therefore investigated in detail the experimental conditions which are necessary to obtain accurate analyses for copper in steels, using an $\mathrm{Fe}-\mathrm{Cu}$ binary alloy as a reference material. With this information we have then examined the fine scale distribution of copper in weld regions of unirradiated low alloy steels. A grain boundary region in an aged $\mathrm{Fe}-\mathrm{Cu}$ alloy specimen has also been examined.

\section{2 - MATERIALS AND EXPERIMENTAL CONDITIONS}

For the initial calibration study, a binary Fe-0.6at.\%Cu alloy was used in the form of $0.13 \mathrm{~mm}$ diameter wire, which was sealed under vacuum, solution treated at $850^{\circ} \mathrm{C}$ for $18 \mathrm{hr}$ and quenched in water.

For the examination of unirradiated weldments, A533B type steels were used, with 'high' copper levels, and 'high' and 'low' nickel levels in order to investigate the effect of nickel in enhancing the copper embrittlement. As part of a larger research programme the full details of the post weld heat treatment are given in [13]. Briefly, this involved a stress relief treatment in the range $600-650^{\circ} \mathrm{C}$. 
Experiments were carried out using the Oxford FIM100 atom probe. The analyses were performed with a system pressure of $10-11_{\mathrm{mb}}$ or less, unless otherwise stated. In a high resolution atom probe there is a risk of some ions being lost, due to the pile up of two or more identical ions at the detector. To minimise this effect the evaporation rate was generally kept below 0.02 ions per pulse, and the data subsequently corrected as explained in [9]. Errors, where indicated, represent one standard deviation. In order to minimise the error range compositions were usually obtained from data blocks of 10,000 ions or more.

\section{3 - CALIBRATION EXPERIMENTS}

The main results are summarised in fig. 1 and Table 1.

(i) Pulse Fraction and Temperature effects.

At a specimen temperature of $96 \mathrm{~K}$ it was not possible to obtain the correct copper concentration at any pulse fraction up to $25 \%$. In order to obtain a valid composition at around $15 \%$ pulse fraction it was necessary to cool the specimen to 50K, fig. 1 .

(ii) Crystallographic Pole.

Analysis close to a (110) pole was compared with results from areas adjacent to (111) and (100). There appears to be some varlation in copper levels, possibly due to a variation in ion trajectories from these regions.

(iii) Laser Pulses.

Due to the brittle nature of some of the materials to be investigated, the use of a pulsed laser system (PLAP) with its lower maximum field stress would seem beneficial. A JK Lasers Nd:YAG system was used in the frequency doubled mode $(\lambda=532 \mathrm{~nm})$. This generated $5 \mathrm{~ns}, 20 \mathrm{~Hz}$ pulses of $<\mathrm{ImJ}$ into an unfocussed, approximately $1 \mathrm{~mm}^{2}$ beam. DC voltage and laser focus conditions at the tip were such that the evaporation rates obtained using the laser pulses were approximately the same as those obtained using voltage pulses at a $15 \%$ pulse fraction. It was not possible at either specimen temperature to obtain the correct value for the copper concentration, the apparent values always being too low. There is need for further work in this area.

(iv) Pulse Frequency.

The laser analyses were obtained at a pulse repetition rate of $20 \mathrm{~Hz}$, whereas voltage pulsing was normally carried out at $50 \mathrm{~Hz}$. This was eliminated as being the cause of the PLAP anomaly by investigating the effect of the voltage pulse frequency at 50K. The results showed some variation but no definite trend could be established.

(v) Presence of Image Gas.

It is advantageous when analysing multiphase materials to observe the image as data is collected. This allows features uncovered by fleld evaporation to be lined up with the probe hole and allows a quantitative depth scale to be calculated. Results obtained in the presence of $2.0 \times 10^{-5} \mathrm{mb}$ of neon did not vary significantly from those obtalned under normal operating pressures.

\section{4 - INTERPRETATION OF CALIBRATION RESULTS}

These results indicate that the Pulse Fraction and Temperature are the major factors influencing the atom probe analyses. The simplest image hump theory of field evaporation, as extended to dilute alloys by Brandon [10] has been used, by Herschitz and Seidman, in a similar investigation [8]. Using the data of Brandon [10] and Tsong [11] the evaporation fields of iron, and copper in iron, can be calculated and compared (Table 2). These values are consistent with the observed pulse fraction effect, namely the preferential field evaporation of copper at the applied d.c. fleld, between pulses, if the pulse fraction is too small.

Table 2. Evaporation fields $\left(\mathrm{Vnm}^{-1}\right)$ of $\mathrm{M}^{\mathrm{nt}}$ in Fe solution

\begin{tabular}{|c|c|c|c|}
\hline $\mathrm{n}=$ & 1 & 2 & 3 \\
\hline $\begin{array}{l}\mathrm{Fe} \\
\mathrm{Cu}\end{array}$ & $\begin{array}{l}42.1 \\
29.1\end{array}$ & $\begin{array}{l}33.2 \\
43.4\end{array}$ & $\begin{array}{l}53.9 \\
77.2\end{array}$ \\
\hline
\end{tabular}


Fig. 1

Effect of pulse fraction and temperature on observed copper concentration.

Table 1. Calibration results.

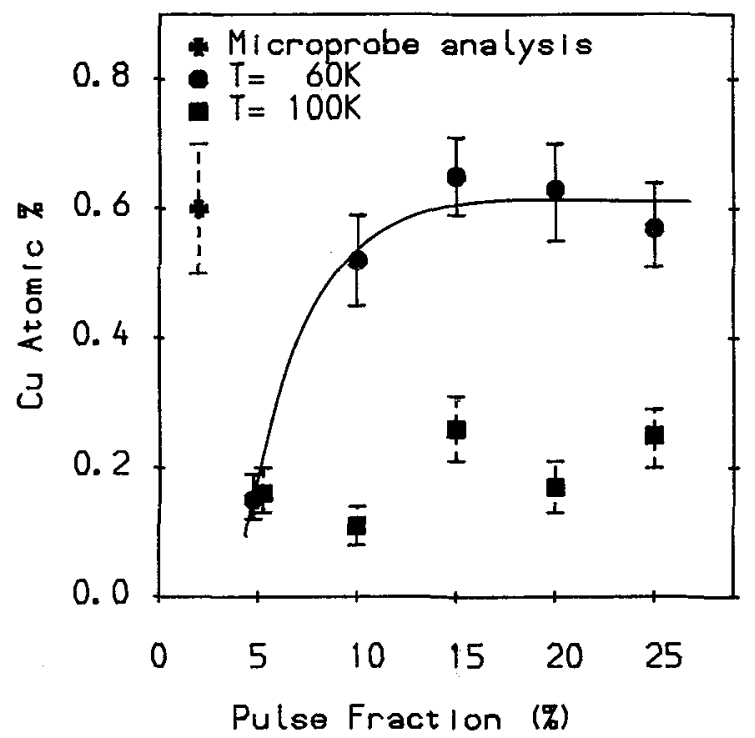

\begin{tabular}{|c|c|c|c|c|c|c|c|c|}
\hline $\begin{array}{l}\text { Text } \\
\text { Ref. }\end{array}$ & $\begin{array}{c}T \\
(\mathrm{~K})\end{array}$ & $\begin{array}{l}\text { Pulse } \\
\text { fraction } \\
(\%)\end{array}$ & $\begin{array}{c}\text { Pulse } \\
\text { frequency } \\
\text { (Hz) }\end{array}$ & $\begin{array}{l}\text { (hk1) } \\
\text { region }\end{array}$ & $\begin{array}{c}\mathrm{Ne} \\
\text { pressure } \\
\text { (mb) }\end{array}$ & $\begin{array}{l}\text { Ion } \\
\text { total }\end{array}$ & $\begin{array}{l}\mathrm{Cu} \\
\text { at. } \%\end{array}$ & Error \\
\hline \multirow[t]{2}{*}{ (i) } & 96 & $\begin{array}{r}5 \\
10 \\
15 \\
20 \\
25\end{array}$ & 50 & 110 & - & $\begin{array}{l}11800 \\
11772 \\
11853 \\
10557 \\
11688\end{array}$ & $\begin{array}{l}0.16 \\
0.11 \\
0.26 \\
0.17 \\
0.25\end{array}$ & $\begin{array}{l}0.04 \\
0.03 \\
0.05 \\
0.04 \\
0.05\end{array}$ \\
\hline & 50 & $\begin{array}{r}5 \\
10 \\
15 \\
20 \\
25\end{array}$ & 50 & 110 & - & $\begin{array}{l}11716 \\
11545 \\
16150 \\
10841 \\
13251\end{array}$ & $\begin{array}{l}0.15 \\
0.52 \\
0.65 \\
0.63 \\
0.57\end{array}$ & $\begin{array}{l}0.04 \\
0.07 \\
0.06 \\
0.08 \\
0.07\end{array}$ \\
\hline (ii) & $\begin{array}{l}50 \\
50\end{array}$ & $\begin{array}{l}15 \\
15\end{array}$ & $\begin{array}{l}50 \\
50\end{array}$ & $\begin{array}{l}100 \\
111\end{array}$ & - & $\begin{array}{l}12118 \\
11297\end{array}$ & $\begin{array}{l}0.52 \\
0.49\end{array}$ & $\begin{array}{l}0.07 \\
0.07\end{array}$ \\
\hline (iii) & $\begin{array}{l}96 \\
50\end{array}$ & $\begin{array}{l}\text { PLAP } \\
\text { PLAP }\end{array}$ & $\begin{array}{l}20 \\
20\end{array}$ & $\begin{array}{l}110 \\
110\end{array}$ & - & $\begin{array}{l}5500 \\
5665\end{array}$ & $\begin{array}{l}0.18 \\
0.25\end{array}$ & $\begin{array}{l}0.06 \\
0.07\end{array}$ \\
\hline (iv) & 50 & 15 & $\begin{array}{l}10 \\
10 \\
20 \\
20 \\
20 \\
50\end{array}$ & 110 & - & $\begin{array}{r}5822 \\
5599 \\
5276 \\
5245 \\
5251 \\
10841\end{array}$ & $\begin{array}{l}0.65 \\
0.59 \\
0.42 \\
0.52 \\
0.48 \\
0.58\end{array}$ & $\begin{array}{l}0.11 \\
0.10 \\
0.09 \\
0.10 \\
0.10 \\
0.07\end{array}$ \\
\hline$*(v)$ & $\begin{array}{l}50 \\
50\end{array}$ & $\begin{array}{l}15 \\
15\end{array}$ & $\begin{array}{l}50 \\
50\end{array}$ & $\begin{array}{l}110 \\
110\end{array}$ & $\begin{array}{c}2 \times 10^{-5} \\
-\end{array}$ & $\begin{array}{l}11776 \\
12059\end{array}$ & $\begin{array}{l}0.37 \\
0.42\end{array}$ & $\begin{array}{l}0.06 \\
0.06\end{array}$ \\
\hline & & & & roprobe & Analysis & & 0.60 & 0.10 \\
\hline
\end{tabular}

(*Image gas experiment performed using a different calibration alloy). 
The observed temperature dependence of field evaporation can be explained qualitatively as a combination of two effects: i) the increased dependence of the evaporation rate, for each element, on the applied field as the temperature is decreased, and ii) the observed greater temperature dependence of the evaporation fleld for pure copper than for iron [12]. At higher temperatures therefore, a pulse fraction in excess of $25 \%$ would be needed to prevent the d.c. evaporation of copper.

\section{6 - COPPER DISTRIBUTION STUDIES}

a) Weld Material. Previous STEM investigations of these specimens using a VG HB5 Field Emission STEM system, gave matrix copper and nickel levels lower than the nominal composition, with some variation between different areas [13]. Atom probe analyses showed considerably greater specimen-to-specimen variation, both above and below the nominal level as shown in Table 3. Although some copper precipitation was observed previously in the STEM, none was found during TEM inspection of field ion specimens, $f i g .2$, or in the atom probe experiments. To test for any departure from a random microdistribution of copper and nickel ions within a given specimen, the observed frequency distributions of these ions were compared with the appropriate binomial distributions and the 'goodness of fit' tested using a Chi squared test. A typical example is given in fig.3. Despite the limited number of copper and nickel ions it can be concluded that the distribution of these ions in individual specimens is random.

Table 3. Maximum and minimum specimen $\mathrm{Cu}$ and $\mathrm{Ni}$ concentrations (atomic\%)

\begin{tabular}{|c|c|c|c|}
\hline & & $\mathrm{Cu}$ & $\mathrm{Ni}$ \\
\hline 'high' Ni & $\begin{array}{l}\max . \\
\min \text {. }\end{array}$ & $\begin{array}{l}0.84 \pm 0.25 \\
0.05 \pm 0.02\end{array}$ & $\begin{array}{l}1.23 \pm 0.31 \\
0.74 \pm 0.10\end{array}$ \\
\hline 'low' & $\begin{array}{l}\max . \\
\text { min. }\end{array}$ & $\begin{array}{l}0.49 \pm 0.15 \\
0.16 \pm 0.04\end{array}$ & $\begin{array}{l}0.22 \pm 0.10 \\
0.14 \pm 0.04\end{array}$ \\
\hline
\end{tabular}

The observed variation between specimens is primarily a consequence of the welding process and subsequent heat treatments. As the weld is built up, in a series of multiple runs, the large temperature gradients and various cooling rates wil1 produce, due to segregation, regions which are either supersaturated, or depleted, in copper or nickel. The solid solubility of copper in iron in the range $600-650^{\circ} \mathrm{C}$ is only $0.15-0.3 \mathrm{wt} . \%$, suggesting that precipitation should occur in copper rich regions during the post weld heat treatment. The observed presence of regions of composition greater than these could be due to the effect of nickel on the copper solubility. Specimens taken from different areas in the weldments would therefore be expected to show some variation.

b) Aged Fe-Cu. These experiments were performed on the older Oxford atom probe. Ageing at $500^{\circ} \mathrm{C}$ for $100 \mathrm{hr}$ produced small (approximately $4 \mathrm{~nm}$ diameter) copper or copper rich precipitates in the Fe-0.6at.\% Cu alloy, of the kind previously observed by Goodman and Brenner [4]. Grain boundary analyses at approximately 50K, showed no observable copper segregation, fig.4. This is in agreement with Miller and Brenner [14], who found no detectable segregation of copper to boundaries in an irradiated steel (analysed at approximately 80K), and tends to confirm that the embrittling mechanism is not a grain boundary phenomenon.

\section{Acknowledgements}

Financial support for this work was provided by the Science and Engineering Research Council and the United Kingdom Atomic Energy Authority, Harwell. GMW wishes to thank UKAEA Harwell for the provision of a CASE Studentship. We are grateful for advice from Dr.C.English (Harwel1), useful discussions with Mr.M.G.Hetherington, and the assistance of Dr.C.R.M.Grovenor and Mr.A.Cerezo with the laser experiments. 
Fig.2 TEM micrograph of 'high'Ni specimen, removed after analysis.

$12 \mathrm{kV} \mathrm{b.i.v.}$

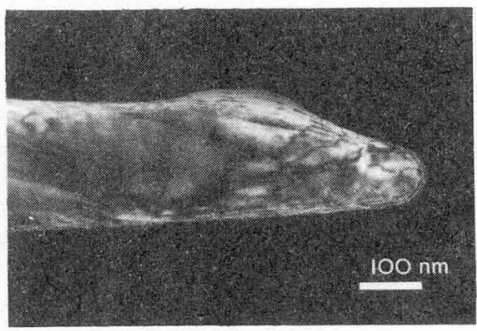

Fig.3 Frequency distributions from two 'high' $\mathrm{Ni}$ specimens compared with the theoretical binomial distributions. A Chi squared test gives probabilities:

a) 0.55

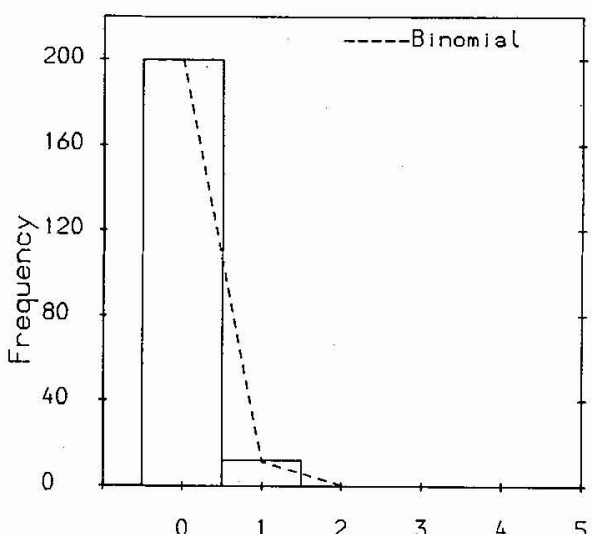

Number of Cu ions in sample of 50 b) 0.21

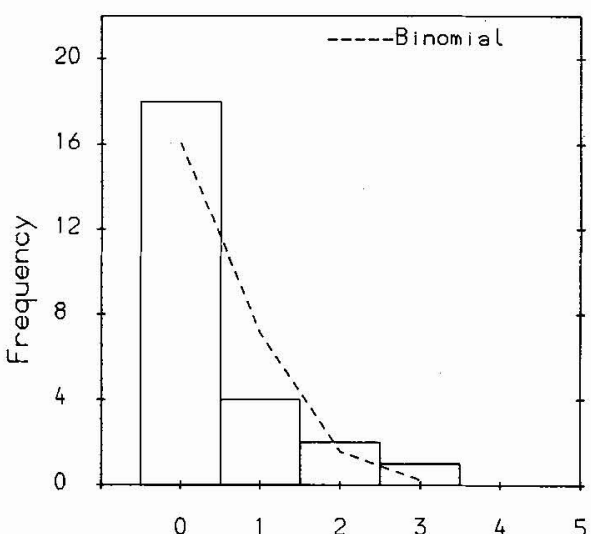

Number of Cu ions in sample of 50 Scan No. 2 1252IONS

Fig. 4

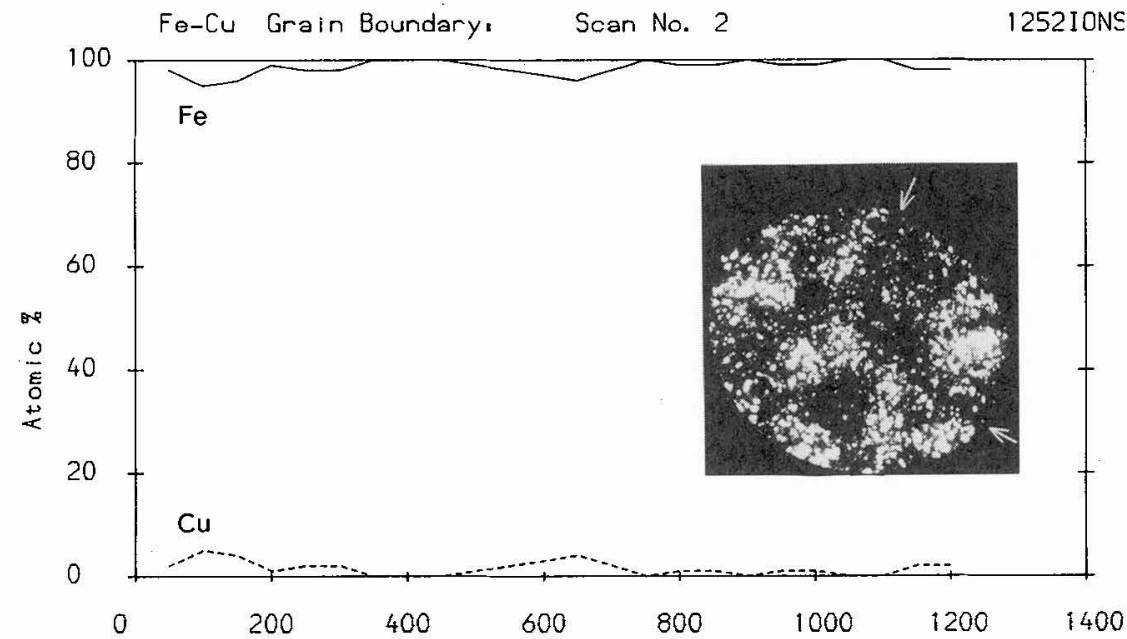

Number of Ions 


\section{References}

[1] Little E.A., in 'Dimensional Stability and Mechanical Behaviour of Irradiated Metals and Alloys', BNES (1984), 141.

[2] Frisius F., Kampmann R., Beaven P.A. and Wagner R., in 'Dimensional Stability and Mechanical Behaviour of Irradiated Metals and Alloys', BNES (1983), 171.

[3] Wagner R., Frisius F., Kampmann R. and Beaven P.A., in 'Reactor Dosimetry' Genthorn J.P. and Rottger H. (eds), (1985), 549.

[4] Goodman S.R., Brenner S.S. and Low J.R., Jr., Met.Trans. 4 (1973), 2363;2371.

[5] Brenner S.S., Miller M.K. and Spitznagel J.A., Met.Trans. 9A (1978), 1761.

[6] Watts A.J., Ph.D. Thesis, Cambridge University (1975).

[7] Miller M.K. and Smith G.D.W., J.Vacuum Sci.Technol. 19 (1981), 57.

[8] Herschitz R. and Seidman D.N., Surf.Sci. 130 (1983), 63.

[9] Cerezo A., Smith G.D.W. and Waugh A.R., J.de Physique 45 (1984), C9-329.

[10] Brandon D.G., Surf.Sci. $\underline{5}$ (1966), 137.

[11] Tsong T.T., Surf.Sc1. 70 (1978), 211.

[12] Wada M., Surf.Sc1. 145 (1984), 451.

[13] Miller M.K. and Brenner S.S., Res Mechanica 10 (1984), 161.

[14] English C.A., to be published in 'Proc. IAEA Specialist Symposium on Radiation Embrittlement and Surveillance of Reactor Pressure Vessel Steels', (1984), ASTM. 